\title{
Access to Healthcare and Lack Thereof for Transgender People
}

\author{
Jamey Merkel ${ }^{1}$
}

\begin{abstract}
Preliminary research on the topic of healthcare for transgender patients, and the many barriers that deny transgender individuals access to appropriate medical care. [Article copies available for a fee from The Transformative Studies Institute. E-mail address: journal@transformativestudies.org Website: http://www.transformativestudies.org (02017 by The Transformative Studies Institute. All rights reserved.]
\end{abstract}

KEYWORDS: Transgender, Healthcare, Healthcare Inequality, Transphobia.

According to the Centers for Disease Control and Prevention (CDC), health equity is "achieved when every person has the opportunity to attain [their] full health potential and no one is disadvantaged from achieving this potential because of social position or other socially determined circumstances" (CDC). True healthcare equity would mean that the systematic differences in aspects of healthcare affecting different groups of people would be gone. The health of all people would be valued, and the highest levels of health for all types of people would be attained. Health equity is not a current reality for many groups of people, especially transgender individuals. The Trans Bodies, Trans Selves textbook provides some insight into this specific issue:

Some social determinants of health are unique to trans people. One of the most important is access to healthcare that is safe and does not discriminate against us because we are trans. This includes hormone therapy and surgical procedures, but we have needs similar to cisgender people too, such as vaccines, treatment of high blood pressure and asthma, and screening for diseases like colon cancer. Unfortunately, transgender people are less likely than cisgender

\footnotetext{
${ }^{1}$ Jamey Merkel - they/them pronouns - Student at SUNY Potsdam, majoring in Women's and Gender Studies.
} 